\title{
Abstract
}

\section{The prevalence of anxiety, depression and sexual maladjustments in post myocardial infarction patients: an uncovered aspect of follow-up care}

Kodithuwakku NW ${ }^{1}$, Bandara HGWAPL ${ }^{1}$, Kogulan $\mathrm{T}^{1}$, Karunaratne RMSP ${ }^{1}$, Hewarathna UI , Jegavanthan $\mathrm{A}^{1}$, Ambagaspitiya AWDT $^{1}$, Dolapihila SNB ${ }^{1}$

${ }^{1}$ Cardiology Unit, Teaching Hospital, Kandy, Sri Lanka

\section{Key words: cardiology, myocardial infarction, anxiety, depression, sexual activity, cardiac} rehabilitation

\section{Background}

Sexual life plays an important role in physical and mental well-being of a patient. Sexual maladjustments therefore may be associated with depression and anxiety contributing to poor quality of life.

\section{Objectives}

To evaluate the prevalence of sexual maladjustments, anxiety and depression among post myocardial infarction (MI) patients.

\section{Methods}

Cross sectional study was conducted at the Cardiology unit, Kandy on a sample of post $\mathrm{Ml}$ patients with a self-administered questionnaire after ensuring patient confidentiality.

\section{Results}

A total of 150 post Ml patients with a mean age of 60 years (range: $37-85$ years) of which $81 \%$ were males, participated in study. The duration following Ml ranged from 0.5 to 5 years. Majority (65\%) had sexual activity within 12 months prior to the cardiac event. However, only $54 \%$ had sexual activity since the Ml, of which $53 \%$ had less frequency, $14 \%$ had the same frequency and $1 \%$ had increased frequency of intercourse while $32 \%$ refused to answer. Only $16 \%$ received instructions on when to resume sexual activity following the MI.

Majority (79\%) had no depression. However, 5\% had depression and $16 \%$ had borderline depression. Most (84\%) had no anxiety disorder. However, 14\% had borderline anxiety and $2 \%$ had anxiety. Prevalence of anxiety $(p=0.397)$ or depression $(p=0.99)$ had no gender disparity.

\section{Conclusion}

Post MI sexual care is a poorly discussed matter. There is a considerable prevalence of borderline depression and anxiety, which need special attention. This study emphasizes the requirement of implementing a cardiac rehabilitation programme in a standard manner to improve safety and quality of life of post MI patients.

Corresponding Author: Naradha Kodithuwakku, Email:< srcardiologynaradha@gmail.com>

Presentation at the $5^{\text {th }}$ biennial academic sessions of the Postgraduate institute of Medicine on 06 October 2016

Competing Interests: Authors have declared that no competing interests exist. 